\title{
COMO O ENFERMEIRO UTILIZA O TEMPO DE TRABALHO NUMA UNIDADE DE INTERNAÇÃO*
}

\author{
Valéria Lerch Lunardi** \\ Wilson Danilo Lunardi Filho*** \\ Marta Riegert Borba****
}

\begin{abstract}
RESUMO: Os autores realizaram uma pesquisa com a colaboração de um grupo de enfermeiros de uma Unidade de Internação de um hospital de ensino. Após a elaboração do rol de atividades passíveis de serem realizadas pelos enfermeiros em sua jornada de trabalho, foi elaborado um instrumento para computar o tempo de trabalho destinado às diversas atividades. O estudo apresenta dados que corroboram a percepção da existência de contradições entre o ensino formal x prática profissional, e procura, por meio da revisão da literatura e de reflexões acerca dos resultados, apontar alternativas de soluções para os problemas detectados.
\end{abstract}

ABSTRACT: The authors carried out a research with collaboration of a nurses' group of an University Hospital. After elaboration of activities list by these nurses in their day's work, an instrument was elaborated to compute the expended time with those several activities. The data confirm the authors' perception about the existent contradictions between "formal teaching $x$ professional practice". It intends, by means of literature's revision and reflections about the results, to point out some alternative solutions to resolve the evidented problems.

UNITERMOS: Unidade de Internação - Atividade do Enfermeiro

\section{INTRODUZINDO A QUESTÃO DA PESQUISA}

A motivação inicial para a realização deste trabalho partiu das experiências vividas, onde afloram contradições, que podem ser verificadas pelo descompasso entre o que se ensina na formação dos enfermeiros e o que é por eles praticado no exercício profissional.

De uma postura inicial de crítica aos enfermeiros por sua possível incompetência em cumpriro que fora preconizado como o seu fazer, postura agora percebida como ingênua e até improdutiva, passamos a nos questionar e refletir sobre as possíveis razões dos mesmos não conseguirem executar, tanto em nível qualitativo quanto quantitativo, o que muitas vezes por eles era feito até o último semestre do curso, quando cursavam a disciplina Administração Aplicada à Enfermagem.

Dessas experiências vivenciadas, analisadas e refletidas, lentamente emergiram contradições entre o que se diz que deve ser realizado pelo enfermeiro e $o$ que é realmente realizado, denotando uma possível visão idealizada, presente no ensino da enfermagem e do fazer do enfermeiro.

* Trabalho apresentado no $45^{\circ}$ Congresso Brasileiro de Enfermagem. Olinda-Recife - PE, 28 de novembro a 3 de dezembro de 1993.

** Prof essora do Curso de Enf ermagem e Obstetricia da Universidade do Rio Grande. Mestre em Educação. FACED-UFRGS.

*** Professor do Curso de Enf ermagem e Obstetrícia da Universidade do Rio Grande. Mestrando em Administração. PPGA-UFRGS.

**** Professora do Curso de Enfermagem e Obstetrícia da Universidade do Rio Grande. Mestranda em Assistência de Enfermagem. Mestrado em Expansão da UFSC. REPENSUL/POLO II - URG.

Foram colaboradoras deste trabalho as enf ermeiras Eliana Pinho Azambuja, Nalu Pereira Keber, Miriam Thereza Ventura Corrêa, Rejane Paim, Cândida Bortolini, Lúcia Lima, And réia Delfino Torres que participaram tanto da elaboração do instrumento de coleta, como da implementação do monitoramento dos dados. 
ALMEIDA e ROCHA ${ }^{(1)}$ destacam que a corrente filosófica idealista é dominante na compreensão da prática da enfermagem, afirmando:

" $O$ discurso da enfermagem é normativo sempre na direção do ideal, do 'deve" ser", e assim as questzes ético-filosóficas são altamente valorizadas e o concreto real com suas contradiçz̃es é escamoteado".

Temos observado que nas unidades de internação do hospital de ensino utilizado como campo de estágio, os enfermeiros executam alguns poucos cuidados diretos de maior complexidade, isoladamente, a um restrito número de pacientes, enquanto que os de menor complexidade são executados predominantemente por outros membros da equipe de enf ermagem. Os demais pacientes, que se constituem na grande maioria, são assistidos por atendentes ou auxiliares de enfermagem, a partir da elaboração da escala e distribuição dos pacientes, quase que com total autonomia em relação aos enfermeiros.

Percebemos também que os enfermeiros são solicitados pelo pessoal auxiliar, quando não conseguem cumprir a prescrição médica, ou executar algum tipo de cuidado em decorrência de problemas inerentes ao paciente ou, mais freqüentemente, em decorrência das condições organizacionais da unidade. Por outro lado, o enfermeiro tem sido constante e continuamente solicitado por outros profissionais da equipe de saúde a envolver-se e a resolver problemas dos mais variados, dizendo ou não dizendo respeito às coisas próprias da enf ermagem, muitos deles por nós considerados como atividades passíveis de delegação a outros elementos, pertencentes ou não à equipe de enfermagem.

Reconhecemos, portanto, o enfermeiro como facilitador do trabalho dos demais membros da equipe de enfermagem e de saúde, podendo realizar, desta forma, muito pouco ou quase nada do que entendemos ou idealizamos ser o fazer do enfermeiro.

TREVIZAN ${ }^{(11)}$ destaca que o enfermeiro executando predominantemente atividades administrativas. Mesmo não representando meio de desenvolvimento e alcance de metas preconizadas pela profissão, realiza uma administração que visa muito mais facilitar o serviço de outros profissionais, do que concretizar os objetivos de seu próprio serviço. Por outro lado, ao não realizar atividades pertinentes ao seu trabalho, e executando outras que não necessariamente precisaria realizar, o enf ermeiro permite a existência de lacunas ou vazios ém sua atuação na área de enfermagem.
Para RIBEIRO(9), não há vazios que não sejam ocupados e, se os espaços fisicos, sociais, culturais ou institucionais que nos cabem, deixarem de ser preocupação nossa, de cada um e de todo o grupo profissional, poderão eles se transformar em problemas maiores para a classe, pois outros tentarão $e$ poderão ocupá-los.

No dizer de SILVA ${ }^{(10)}$, ocorreu na enfermagem uma fragmentação de seu objeto de trabalho, onde a assistência de enf ermagem ficou subdividida em cuidados direto e indireto, sendo que o primeiro quase que totalmente restrito às diversas categorias dos demais profissionais supervisionados pelo enfermeiro. Segundo esta autora, a ameaça de descaracterização que envolve a profissão de enfermeiro advém de seu papel de governanta e não de seu papel de supervisor da assistência ao doente. $\mathrm{O}$ fato do enfermeiro não prestar o cuidado direto não diminui a importância de seu trabalho que se vincula àquele cuidado, zelando por sua qualidade, pelo menos hipoteticamente.

LEOPARDI et al.(7) referem que esta divisão determinada historicamente, expressa-se pela divisão do trabalho executado em assistencial e administrativo. Os enfermeiros admitem essa divisão, mas tendem a supor que somente poderão sentir-se gratificados quando estão juntos do paciente, o que denominam assistência direta. Ao expressarem sua posição acerca do trabalho que realizam, enfatizam seus sentimentos de culpa, ao fazerem mais administração do que o cuidado direto. Para estes autores, não se pode fazer uma caracterização da assistência de enfermagem como se esta fosse universal e homogênea. Temos de considerar que $o$ ato de assistir modificou-se ao longo do tempo e a enfermagem passa por uma organização interna, de modo que aparece um profissional que, além de possuir um amplo conhecimento da biologia humana, ainda assume papéis impostos pela nova estrutura organizacional do hospital e outras instituições de saúde. Assistir inclui, então, o gerenciamento do meio hospitalar e a coordenação de um trabalho que se divide não só por especialidades, mas por complexidade. Tarefas simples, medianas e complexas da assistência passam a ser distribuídas a diferentes elementos de uma equipe. $\mathrm{O}$ assistir tomase um trabalho coletivo.

Portanto, diante destas constataçð̃es, e da contradição entre o que se preconiza na formação e o que se poderia configurar como crenças e aspiraç̃es quanto o fazer do enfermeiro e o que se evidencia durante o seu exercício profissional, em que se adapta ao espaço 
e funções que lhe são oferecidos e propostos no campo de trabalho, buscou-se com a realização deste trabalho:

- identificar, numa unidade de intemação de um hospital de ensino, as atividades desempenhadas pelo enfermeiro e que constituem o seu fazer;

- identificar o tempo destinado pelo enfermeiro à execução de atividades administrativas, assistenciais e não especificas.

Neste trabalho, apoiamo-nos na denominação já utilizada por MENDES(8) de funções assistenciais, administrativas e outras funções não especificas do enfermeiro. Consideramos como:

- atividades administrativas: aquelas que envolvem a coordenação da assistência e concorrem, portanto, para o adequado atendimento do paciente. Os cuidados indiretos de enfermagem, pertinentes à administração da assistência de enfermagem, constituem esse grupo de atividades.

- atividades assistenciais: aquelas executadas pelo enfermeiro diretamente ao paciente, envolvendo conhecimentos e habilidades técnicas pertinentes à sua formação. Compreendem o conjunto de atividades privativas, ou não, do enfermeiro, que constituem o que denominamos de cuidados diretos de enfermagem.

- atividades não especificas: aquelas que devido a suas características intrínsecas não necessitam ser realizadas por profissional com formação de enfermeiro, podendo ou não exigir conhecimentos pertinentes à enfermagem.

Ressaltamos que esta busca configura-se num primeiro movimento, na tentativa de desvelar e entender a dicotomia presente entre o que se diz que deveria ser e o que é, buscando uma aproximação tanto da prática à tcoria, como da teoria à prática.

Parece-nos importante destacar que a profissionalização da enfermagem processou-se, basicamente, através de duas categorias sociais distintas, consoante ao modelo nightingalcano, cujas metas eram o preparo de pessoal de classe social mais baixa para o exercício de serviços usuais de enfermagem hospitalar e domiciliar, e o preparo de pessoas de classe mais alta para as atividades de supervisão, administração e ensino( ${ }^{(1)}$. Esta dicotomia do trabalho em intelectual e manual caracteriza, no início da enfermagem moderna, a divisão social do trabalho dissimulada sob a forma de divisão técnica do trabalho, favorecendo a espoliação das classes dominadas, que internalizam a percepção dominante de que as tarefas que executam são, socialmente, menos importantes. Consideramos que este fato histórico ainda tem sido negado, ou pouco explorado, na formação dos enfermeiros.

\section{DESCREVENDO O MÉTODO}

Selecionamos a única Unidade de Internação (UI) que, à época, se encontrava em funcionamento no prédio novo, ainda em construção, do hospital de ensino da Universidade do Rio Grande (URG). Tratava-se de uma UI de Clínica Médica, organizada para atender até o máximo de quarenta e quatro (44) pacientes, por uma equipe de enfermagem distribuída em três turnos, nos horários das sete às treze horas e trinta minutos, das treze às dezenove horas e trinta minutos e das dezenove horas às sete horas e trinta minutos.

Nos turnos da manhã, tarde e em noites alternadas, estavam lotados três (3), dois (2) e um (1) enfermeiros, respectivamente, e como pessoal auxiliar, fundamentalmente, atendentes de enfermagem, em número de nove (9), sete (7) e em cada noite, cinco (5). Esta UI dispunha de uma secretária administrativa com jomada de quarenta (40) horas de trabalho semanais, de segunda a sexta-feira.

Após a realização de vários encontros com as enfermeiras lotadas nesta UI, também preocupadas em demonstrar cientificamente como empregavam o seu tempo de trabalho no hospital, decidiu-se pela realização de um instrumento, o qualviria a ser preenchido pelas próprias enfermeiras, durante o seu turno de trabalho. A partir de uma listagem das atividades por elas realizadas durante o expediente de trabalho, elaboramos um primeiro instrumento que, depois de testado e reformulado, de modo a facilitar o monitoramento do emprego do tempo pelas próprias enfermeiras, constituiu-se no instrumento utilizado para o prosseguimento da coleta dos dados. Iniciou-se a coleta dos dados em julho de 1990, finalizando em dezembro do mesmo ano.

\section{DESCREVENDO E ANALISANDO OS RESULTADOS}

No processo de elaboração do instrumento para a monitorização do tempo, obteve-se a relação de atividades passiveis de serem executadas pelos enfermeiros na unidade de intemação em estudo. Estas foram classificadas pelos autores do trabalho como atividades administrativas, assistenciais e não especificas:

R. Bras. Enferm. Brasilia, v. 47, n. 1, p. 7-14, jan./mar. 1994 


\section{Atividades administrativas}

- Visitar pacientes.

- Revisar prontuários.

- Encaminhar pacientes para exames complementares.

- Comunicar ao funcionário novas prescrições médicas.

- Conversar com o médico sobre o paciente.

- Registrar no livro de ocorrências.

- Realizar evolução de enfermagem.

- Realizar prescrição de enfermagem.

- Comunicar internação ao funcionário responsável.

- Passar plantão.

- Elaborar escala de divisão de enfermarias.

- Contactar com nutricionista.

- Encaminhar paciente à assistente social.

- Contatar com assistente social.

- Controlar medicação controlada.

- Revisar o carro de urgências.

- Instalar isolamento.

- Orientar funcionários sobre isolamento.

- Supervisionar o preparo do corpo pós-morte.

- Comunicar e orientar familiares sobre o óbito.

- Elaborar a escala de serviço.

- Fechar prontuário.

- Realizar treinamento em serviço.

- Realizar supervisão do desempenho cionário.

- Elaborar escala de férias.

- Encaminhar atestados para o Departamento de Pessoal.

- Solicitar carta de advertência.

- Realizar reuniðes com a equipe de enfermagem.

- Realizar reunião individual com funcionário.

- Realizar reunião com a equipe multidisciplinar.

- Elaborar escala de limpeza.

- Realizar supervisão do pessoal de limpeza.

- Realizar supervisão da limpeza e desinfecção do material.

- Divulgar comunicaçð̃es recebidas.

- Revisar literatura.

- Ler livro de ocorrências.

- Revisar exames.

- Orientar funcionários.

- Encaminhar folha de efetividade.

- Orientar familiares.

\section{Atividades Assistenciais}

- Realizar punção venosa.

- Aplicar insulina.

- Realizar haemoglicotest.

- Realizar sondagem vesical.

- Realizar sondagem nasogástrica.

- Realizar sondagem retal.

- Instalar abocath/venocath.

- Realizar aspiração endotraqueal/orofaríngea.

- Colocar catéter nasal.

- Trocar catéter nasal.

- Realizar curativo de flebotomia/intracath.

- Realizar curativos.

- Instalar PVC.

- Ler PVC.

- Realizar assistência em parada cárdio-respiratória.

- Realizar assistência em edema agudo de pulmão.

- Realizar assistência no choque.

- Realizar assistência em urgências em geral.

- Controlar sinais vitais.

- Preparar quimioterapia.

- Instalar quimioterapia.

- Realizar assistência em drenagem de tórax.

- Auxiliar no transporte do paciente.

- Administrar medicamentos.

- Trocar soros.

- Observar características das eliminações.

- Realizar admissão do paciente.

- Orientar paciente para alta.

- Auxiliar o médico nos procedimentos.

- Pesar e medir o paciente.

\section{Atividades Não Especificas}

- Distribuir frascos de exames.

- Recolher frascos de exame.

- Aprazar prescrições médicas.

- Prover material para a unidade.

- Prover medicação para a unidade.

- Atender telefone.

- Dar informação sobre paciente por telefone.

- Pedir ligação telefônica e aguardar.

- Localizar médicos das enfermarias.

- Localizar médico de plantão.

- Anotar em formulário próprio encaminhamento ao raio $\mathrm{X}$.

- Localizar funcionários na unidade.

- Conferir e guardar material em estoque. 
- Preparar material para procedimentos.

- Ver disponibilidade de leitos para internação.

- Supervisionar leito antes da chegada do paciente.

- Comunicar internação ao médico responsável.

- Comunicar Serviço de Nutrição sobre nova internação.

- Preencher formulário de alta.

- Comunicar Serviço de Nutrição sobre dietas.

- Elaborar lista de dietas.

- Fornecer boletim médico para plantão médico.

- Conferir a medicação.

- Estornar medicação para a farmácia.

- Pedir material.

- Levantar material.

- Revisar material permanente.

- Manter controle de 02.

- Solicitação de consertos.

- Realizar ECG.

- Solicitar ticket de almoço.

- Encaminhar ticket de almoço.

- Autorizar exames.

- Arquivar folhas no prontuário.

Parece-nos que diante do rol de atividades descrito pelos enfermeiros como passíveis de serem por eles realizadas, toma-se mais uma vez evidente a dicotomia teoria-prática, com uma profunda dissonância entre o que é dito que o enfermeiro deve fazer, e o que o mesmo executa de fato. Sabe-se, no entanto, que esta constatação já foi denunciada por vários autores como ALMEIDA e ROCHA(1), BLANK(3), HARMER e HENDERSON(6), SILVA(10) e TREVIZAN(11), entre outros e, no entanto, a ênfase nos cursos de graduação ainda tem sido para a prestação do cuidado direto aos pacientes, com uma visão por vezes até pejorativa da prestação do cuidado indireto.

ALMEIDA e ROCHA(1), dizem que o ensino é caracterizado como paradigma do saber, esquecendose que é no trabalho que se deve buscar os elementos do saber. É no desenvolvimento do cuidado de enfermagem, que opera diretamente com o objeto - o doente - e no qual se desenvolvem as relações técnicas e sociais, que está a essência do saber. No ensino, o objeto de trabalho continua sendo apresentado como fundamentalmente o cuidado ao paciente, mas na prática, tem sido predominantemente a gerência dos serviços e o controle do pessoal e do material. $O$ distanciamento entre o ensino e a prática, sendo cada vez mais polar, origina uma barreira que separa os que ensinam a prática e os que a praticam.
$\operatorname{BLANK}^{(3)}$ refere que a formação profissional do enfermeiro, centrada no cuidado direto ao paciente, ensinando que este é o objeto de sua prática, é uma das contradições entre a relação ensino formal x prática profissional. Ressalta que a função primordial continua sendo, basicamente, gerencial: administrar, supervisionar e disciplinar a prática da enfermagem, ou seja, monopolizar o conhecimento e controlar o trabalho dos elementos auxiliares de sua equipe.

TREVIZAN(11) refere que os alunos são introduzidos a um papel profissional, aprendendo a valorizar o cuidado individualizado ao paciente, em bases científicas, durante todo o processo de educação profissional. As escolas de enfermagem enfatizam o cuidado individual ao paciente, enquanto o hospital, o maior empregador de enfermeiros, espera que eles verifiquem a execução das ordens médicas e se são seguidas as rotinas hospitalares. Parece-nos que, enquanto aparelho ideológico, a escola tem produzido e reproduzido fundamentalmente a imagem do enfermeiro como prestador de cuidados.

Apesar destas repetidas constataç̃es do afastamento da teoria da prática, e desta da teoria, temos nos perguntado se a incompetência dos docentes e dos enfermeiros em aproximar a teoria da prática e a prática da teoria, estariam relacionadas à sua formação disciplinar, a qual os tem levado a apresentar uma maior produtividade econômica com concomitante redução de produtividade política. Entendemos produtividade econômica como a necessidade de fazer, de mostrar trabalho, de ocupar contínua e produtivamente o tempo, e como redução de produtividade política, a docilização que envolveria a adaptação, o conformismo e a sujeição ao que aí está, como normas, rotinas e exigências institucionais. O que levaria os enfermeiros a assumirem como atividade de sua competência, a realização de ECG ou o fornecimento de boletim médico para o plantão, entre outras funçðes? Seria a necessidade de mostrar trabalho e/ou, que jogos de poder estariam aí inseridos?

Prosseguindo na análise dos dados, evidencia-se um possível conformismo ou improdutividade política diante do tempo destinado pelo enfermeiro, especialmente, no que se refere às atividades por nós entendidas como não especificamente suas.

Da coleta dos dados pertinentes à utilização do tempo/turno monitorado pelas enfermeiras, desprezando-se o tempo dispensado para o lanche, variável de quinze a trinta minutos, obteve-se 109 horas e 59 minutos controladas e assim distribuídas: 
Turno da manhã: 45 horas e 22 minutos

Turno da tarde: 46 horas e 6 minutos

Turno da noite: 18 horas e 31 minutos

Após o cômputo das atividades e do tempo utilizado, obtivemos os seguintes resultados parciais:

\section{Turno da manhã:}

- $42,88 \%$ do tempo utilizado em atividades administrativas;

- $15,27 \%$ do tempo utilizado em atividades assistenciais;

- $41,85 \%$ do tempo utilizado em atividades não específicas.

\section{Turno da tarde:}

- $48,25 \%$ do tempo utilizado em atividades administrativas;

- $13,83 \%$ do tempo utilizado em atividades assistenciais;

- $37,92 \%$ do tempo utilizado em atividades não específicas.

\section{Turno da noite:}

- $37,62 \%$ do tempo utilizado em atividades administrativas;

- $23,85 \%$ do tempo utilizado em atividades assistenciais;

- $38,53 \%$ do tempo utilizado em atividades não específicas.

\section{Como resultado geral obtivemos:}

- $42,92 \%$ do tempo utilizado em atividades administrativas;

- $17,65 \%$ do tempo utilizado em atividades assistenciais;

- $39,43 \%$ do tempo utilizado em atividades não específicas.

De posse dos resultados, pode-se verificar que há um predomínio das atividades administrativas $(+2,92 \%)$ e das atividades não específicas do enfermeiro $(39,43 \%)$.

As administrativas, referentes à coordenação da assistência, no nosso entendimento, assim como nos de TREVIZAN(11), BLANK(3), $\operatorname{SILVA}^{(10)}$, ALMEIDA e ROCHA ${ }^{(1)}$, constituem o fazer necessário e imprescindivel ao enfermeiro, de modo a garantir a assistência de saúde requerida aos pacientes sob sua responsabilidade.
Provavelmente, o baixo percentual de atividades assistenciais identificado (17,65\%), resulta do modo como o hospital, como um todo, está organizado, repercutindo de tal sorte na organização do serviço de enfermagem, que tem mobilizado o trabalho do enfermeiro em direção a atividades por nós entendidas como não especificas.

$\mathrm{O}$ elevado índice evidenciado destas atividades não especificas contribui para tal percepção, pois têm sido realizadas, aparentemente, sob o pretexto de serem necessárias ao bom andamento do serviço, com vistas a sua agilização e eficácia, em nome do atendimento das necessidades do paciente. Porém, parecenos que sua realização visaria muito mais facilitar 0 serviço de outros profissionais, do que concretizar seus próprios objetivos, não representando meio de desenvolvimento e alcance das metas preconizadas pela profissão.

Acreditamos que tais atividades, consideradas como não específicas do enfermeiro, têm sido percebidas como sendo atividades administrativas; percepção esta que, no nosso entendimento, talvez seja a responsável pelo caráter pejorativo que se incorporou às últimas, desencadeando a negação da importância que representam na assistência global de enfermagem.

MENDES(8), ao buscar identificar as funções que os enfermeiros da Região Metropolitana de Belo Horizonte desempenhavam na prática profissional, em março de 1982, obteve, no que concerne à carga horária destinada pelos enfermeiros às funções administrativas, índices próximos aos por nós identificados $(40,8 \%)$. No entanto, a carga horária destinada às funções assistenciais $(40,1 \%)$ e a funções não específicas do enfermeiro $(19,1 \%)$ apresentam quase que uma inversão aos nossos achados. Tais resultados servem para corroborar nossa percepção do possível comprometimento da organização da unidade de internação em estudo, e/ou do hospital de ensino como um todo.

Portanto, frente aos resultados encontrados, decorrem, inicialmente, dois eixos de análise: o primeiro, relativo à organização do serviço de enfermagem no que concerne aos recursos materiais e humanos e à definição de atribuições; o segundo, compreendendo a questão da competência do enfermeiro, que poderia estar ligada, entre outras razões, à sua formação, e como o seu fazer está sendo analisado, refletido e preconizado.

HARMER e HENDERSON( ${ }^{(6)}$, já há mais de três décadas, recomendavam que o enfermeiro limitasse 
suas atividades à enfernnagem especificamente, destinando a outros as numerosas funções tradicionalmente executadas por ele, como provisionamento de material, esterilização de material e equipámentos, limpeza, etc. Por outro lado, recomendavam que o enfermeiro se responsabilizasse por pacientes que apresentassem problemas mais complexos, confiando ao pessoal auxiliar aqueles com cuidados menos complexos, exercendo a supervisão de todos os pacientes e/ou a execução de procedimentos mais complexos incluídos nos planos de cuidados. Reforçavam, ainda, que a administração e o ensino, a anotação nos registros dos cuidados de enfermagem, constituíam parte integral de sua função.

$\operatorname{SILVA}^{(10)}$ relata que na transição da enfermagem tradicional para a enfermagem modema, a crescente divisão do trabalho e o processo de cientifização da categoria dos enfermeiros, contribuíram para complicar o problema das indefinições de funções entre as categorias de enfermagem aprofundando, em seu interior, a divisão entre trabalho intelectual e trabalho manual.

ANGERAMI e $\operatorname{ALMEIDA}^{(1)}$, ao analisarem a inserção do enfermeiro no seu espaço, também destacam a irregularidade de fronteiras: tanto outros profissionais assumem o que é de competência do enfermeiro, como se dá o inverso. Do mesmo modo, evidenciam que o espaço profissional do enfermeiro é preenchido também por técnicos, auxiliares e atendentes e que, apesar de diferentes níveis de formação e salários diferenciados, a realidade mostra limites frouxos no seu fazer, quando executam, de modo indiscriminado, as mesmas funções. Os dados acerca do tempo destinado à realização de atividades não específicas do enfermeiro, que no turno da noite até ultrapassam o tempo designado às atividades administrativas, demostram tanto esta fragilidade de fronteiras denunciada por ANGERAMI e $\operatorname{ALMEIDA}^{(1)}$, quanto a possível capacidade de adaptação dos enfermeiros ao que a instituição lhes solicita ou exige.

Daí decorre perguntarmos: até que ponto esta capacidade de adaptação dos enfermeiros estaria relacionada à sua formação? Até que ponto esta capacidade de adaptação estaria também relacionada ao enfatizado em sua formação como sendo iniciativa, ou seja, diante da inexistência de quem deveria fazer, o enfermeiro assume este fazer, seja por um ato de abnegação aos pacientes ou de sujeição a quem detém o poder? Parece ser mais fácil nestes jogos de poder em que os enfermeiros estão inseridos, estes tentarem resolver as dificuldades que enf rentam com as armas de que dispõem, como a dita iniciativa e a aptidão para o trabalho, do que enfrentarem quem tradicionalmente representa o poder, como as chefias de enfermagem ou a administração dos hospitais, na busca de mudanças que possibilitem o exercício, tanto da coordenação da assistência, como da realização de cuidados mais complexos aos pacientes.

Acreditamos que este tipo de indefinição tem serviço aos interesses empresariais das instituiçð̃es de saúde, que justificam a utilização de mão-de-obra com menor qualificação apenas para o desempenho de técnicas de enf ermagem tidas como menos complexas. A Lei 7.498, de 25 de junho de $1986^{(4)}$, que dispõe sobre o exercício da enfermagem, ao estabelecer as categorias do pessoal de enfermagem, legitima a divisão técnica do trabalho dentro da profissão. Ao enfermeiro é legalmente permitido o exercício de todas as ações de enfermagem, sendo-lhe facultadas algumas privativas porém, geralmente, faltam-lhe condições nas diferentes instituições de saúde para poder exercê-las. Na prática, como já evidenciado por ANGERAMI e ALMEIDA(1), em geral, todas as demais categorias fazem tudo, cabendo predominantemente ao enfermeiro o desempenho de atividades gerenciais.

Parece imprescindivel destacar o papel da organização do hospital no que conceme aos recursos materiais e humanos necessários à prestação de assistência de saúde, como à questão da delimitação de espaços e funções.

Neste sentido, é importante e urgente a discussão e o aprofundamento sobre os objetos de trabalho dos enfermeiros (que se percebe não ser único, face às diversas funções que desempenham, como gerenciais, assistenciais e educativas), bem como, sobre a organização do processo de trabalho da enfermagem.

Há ainda que se refletir sobre a instrumentalização dos enfermeiros para a mudança, como tem-se dado a sua formação, o destaque e grande valorização à obediência às normas ou às determinaçð̃es dos docentes, e a baixa valorização ao questionamento, à reflexão ou até a possíveis movimentos de resistência dos alunos. GERMANO(5) enf atiza e critica o papel relevante que a obediência, a abnegação e a dedicação historicamente têm na enfermagem desde a sua origem, o que tem levado à formação de profissionais obedientes e disciplinados, mas submissos nas relações de poder.

Destacamos ainda o caráter feminino da enf ermagem, exercida predominantemente por mulheres, e a influência direta e indireta das relações de gênero, 
entendido como uma construção social do sexo, sobre a profissão. Sabe-se que faz parte do estereótipo feminino, a delicadeza, a docilidade e diríamos até, a não agressividade. Além destas características próprias do gênero feminino que favoreceriam uma postura mais conformista, ressaltamos a preparação da mulher para o doméstico, que teria muito a ver, no nosso entendimento, com o fazer do enfermeiro. Este, ao assumir a unidade de internação não tem se limitado à coordenação da assistência de enfermagem e à prestação de assistência direta, o que por si só se constituem numa imensa tarefa, mas também assume um papel de governanta, comprometendo ainda mais o seu fazer.

\section{4. À GUISA DE CONCLUSÃO}

O presente trabalho coloca em evidência, de forma contundente, as discrepâncias entre o que é preconizado pela escola como o fazer do enfermeiro e 0 que é por ele realizado no exercício profissional.

Demonstra, concretamente, a necessidade de se repensar a teoria e a prática profissional do enfermeiro, levando em consideração os aspectos relativos ao estabelecimento de sua competência, consoante à definição de seus objetos de trabalho.

Concordamos com LEOPARDI et al. ${ }^{(7)}$ quando dizem que o trabalho do enfermeiro passa por um processo de transição que se observa pela identificação de vários objetos de trabalho, pela compreensão do que seja sua competência, pela divisão do trabalho entre os vários agentes, pela finalidade do mesmo e pelas limitaç̃̃es para sua realização. $O$ papel administrativo na assistência de enfermagem não deve ser visto como pólo oposto do cuidado mas, pelo contrário, agregado a este cuidado, e nem visto como uma atividade tomada como se não fosse objeto do enfermeiro.

Deve-se ter presente que a enfermagem enquanto uma atividade concreta, material e produtiva, tem como finalidade a prestação de assistência à saúde das pessoas sendo, portanto, este o objeto sobre o qual se aplica o seu fazer.

O trabalho do enfermeiro, juntamente com o dos demais integrantes da equipe de enfermagem, deve concorrer para $\mathrm{o}$ alcance pleno desta finalidade. Para tanto, faz-se necessária atenção às questões pertinentes à organização do hospital como um todo, assim como, do processo de trabalho da enfermagem, e de estabelecerem-se os limites de competência de cada categoria que atua dentro da profissão, apesar da aprovação da lei do exercício profissional.

Deve-se repensar tanto as ênfases presentes na formação dos enfermeiros, quanto no como tem se dado essa formação, no sentido de clarear e até desvelar, os aspectos relativos à competência profissional, entendida como competência técnica e também política, instrumentalizando-os para as mudanças que se fazem necessárias para a concretização dos objetivos da profissão.

\section{REFERÊNCIAS BIBLIOGRÁFICAS}

1. ALMEIDA, M.C. de e ROCHA, J. S.Y. O saber da enfermagem e sua dimensão prática. São Paulo: Cortez, 1989.

2. ANGERAMI, E.L.S. e ALMEIDA, M.C.P. de. De como o enfermeiro está inserido no seu "espaço". In: Rev. Bras. de Enf., Brasília, v.36, n.2, p. 123-129, 1983.

3 BLANK, V.L.G. Contribuição ao estudo da prática de enfermagem. Rio de Janeiro. Escola Nacional de Saúae Publica da Fundação Oswaldo Cruz, 1987. Dissertação de Mestrado.

4. BRASIL. Lei número 7.498 , de 25 de junho de 1986. Dispõe sobre a regulamentação do exercício da enfermagem e dá outras providências.

5. GERMANO, R.M. Educação e ideologia da enfermagem no Brasil. 2 ed., São Paulo: Cortez, 1985.

6. HARMER, B. e HENDERSON, V. Tratado de enfermeria teorica y práctica. 2 ed., México: La Prensa Médica Mexicana, 1975.
7. LEOPARDI, M. T. et al. O significado da assistência de enfermagem no resultado da assistência à saúde. Rev. Bras. Enf., Brasilia, v.45, n.4, p.249-258, out/dez, 1992.

8. MENDES, D. de C. Assistência de enf ermagem e administração de serviços de enf ermagem: a ambiqüidade funcional do enfermeiro. Rev. Bras. Enf., Brasília, v.38, n.3/4, $\mathrm{jul} / \mathrm{dez}, 1985$.

9. RIBEIRO, C.M. Discurso de posse. Congresso Brasileiro de enf ermagem, 32, Brasilia, jun1-7, 1980. Anais, Brasília, ABEN, 1980, p.21-23.

10. SILVA, G.B. Enfermagem profissional. 2 ed. São Paulo: Cortez, 1989

11. TREVIZAN, M.A. Enfermagem hospitalar: administração e burocracia. Brasilia: Editora da Universidade de Brasilia, 1988.

Recebido para publicação em 15.12.93 